\title{
Labor Market Resource Allocation Optimization Based on Principal Component Analysis
}

\author{
Xiaojing Liu (i) \\ Business School, Anyang Normal University, Anyang, Henan 455000, China \\ Correspondence should be addressed to Xiaojing Liu; 01160@aynu.edu.cn
}

Received 23 November 2021; Accepted 22 December 2021; Published 3 February 2022

Academic Editor: Miaochao Chen

Copyright (c) 2022 Xiaojing Liu. This is an open access article distributed under the Creative Commons Attribution License, which permits unrestricted use, distribution, and reproduction in any medium, provided the original work is properly cited.

\begin{abstract}
As an endogenous mechanism affecting social and economic changes, the allocation of labor affects the overall efficiency and comprehensive level of economic development in a region. Firstly, this paper collects and analyzes the data from 2011 to 2020 , then screens out useful data, and predicts the relevant data of the three major industries in 2021 by the grey prediction method and curve fitting method. Secondly, the principal component analysis is used to calculate the weights of indicators such as market share, industrial growth rate, employment contribution rate, and the pulling ability to GDP, and then the strength of each industry is calculated. Finally, the strong industries are determined according to the principle of increasing the intensity of strong industries, so as to provide suggestions for the optimization of the allocation of labor market resources in the three major industries.
\end{abstract}

\section{Introduction}

China's GDP consists of three industries, and the primary industry is the foundation of the secondary and tertiary industries, which plays a fundamental role. Generally speaking, the higher the proportion of secondary and tertiary industries in the national economy, the stronger the economic strength of the country. The development process of industrialization shows that the proportion of manufacturing industry increases rapidly, which leads to the transfer of labor from agriculture to manufacturing industry, so that the proportion of labor in the secondary industry increases rapidly, while the proportion of labor in the primary industry decreases rapidly. However, with the further development of economy, the proportion of labor force in the tertiary industry has increased rapidly and accounted for the largest proportion $[1,2]$. As the most flexible factor in production factors, labor force directly or indirectly affects the allocation of other factors. Therefore, labor resources are the key factors in the development of three major industries in the process of economic and social development $[3,4]$.

Labor resources have an irreplaceable importance as the only key resource with independent initiative in the industry. However, there is still a serious shortage of directional training before employment and skill training after employment in China at present, which cannot enable workers to update their knowledge and improve their skills to meet the needs of new industries, new departments, and new occupations [5]. Therefore, it is crucial to optimize the allocation of labor resources. The optimal allocation of labor resources is a static concept and a dynamic concept [6]. From a static point of view, it represents the rationality of the allocation of labor resources in today's society. From a dynamic perspective, it indicates that the allocation of social labor resources in the future will be adjusted accordingly with the change of industrial structure, so as to make the optimal allocation. From the perspective of marketization, the allocation of labor resources includes not only the introduction of high-level talents but also the cultivation of specific professional labor force needed for social development according to market requirements to meet the needs of different levels of labor force for economic and social development.

The composition and allocation efficiency of labor resources determines the development speed and output value of the three industries. Therefore, it is necessary to explore the better allocation of labor resources in the industry and improve the existing allocation of labor resources $[7,8]$. On 
the one hand, the imperfect allocation mechanism of labor market resources will affect the horizontal fairness and vertical fairness. The horizontal equity means that labor can enjoy fair employment opportunities by improving the optimal allocation mechanism of labor resources. The vertical equity refers to the improvement of working skills of the labor force through continuous vocational training in work, which can improve wages. On the other hand, the unreasonable allocation of labor resources will bury many excellent talents, which causes a lot of waste or shortage of talents in society. Some talents are refused employment because of unreasonable treatment, which shows that they lost equal employment opportunities, so that they cannot achieve employment and re-employment. These problems are not conducive to social stability and economic development. We hope to improve economic efficiency by optimizing the allocation of labor market resources and narrowing regional economic development differences $[9,10]$.

Therefore, this paper takes China's labor market as the research object and selects the macrodata of the three major industries from 2011 to 2020. Then, we use the grey model and curve fitting method to predict the market share, industrial growth rate, employment contribution rate, and GDP pulling capacity of the three major industries in 2021 and use the principal component analysis method to determine the strong industries, so as to provide suggestions for the optimization of labor market resource allocation in the three major industries.

The innovation contribution of this paper is to select more accurate prediction data by comparing the results of the two prediction methods and then use principal component analysis and prediction results to determine the strong industries of China's three major industries, so as to put forward reasonable policy recommendations for the allocation of labor market resources. This paper is organized as follows. Section 1 expounds the importance of labor resources and the significance of studying the allocation optimization of labor market resources. Section 2 summarizes the literature research related to resource allocation. Section 3 elaborates the basic theory and modeling process of the grey prediction method and curve fitting method as well as principal component analysis method. Section 4 is based on the four indicators of market share, industrial growth rate, employment contribution rate, and GDP pulling ability of three major industries to determine the strong industry. Finally, Section 5 provides suggestions for the optimization of labor market resource allocation in the three industries.

\section{Related Work}

Resource allocation refers to a country's rational planning and allocation of available resources among various industries and sectors to cope with the limitation of resources with the optimal allocation of resources. In recent years, the scholars' research on resource allocation optimization has never stopped. Many scholars in various countries used different methods to optimize the allocation of various resources. Throughout the existing literature analysis, research on the national level is relatively more. For example, Zhou et al. [11] used the principal component analysis method to cluster the charging station resources in different regions, then constructed the charging station configuration optimization model, and used the Floyd algorithm to analyze and evaluate the effect of the established charging station configuration optimization model. This article provides a basis for promoting the modernization of urban green transportation. It is crucial for managing and allocating water resources [12], so Kazemi et al. [13] established a multiobjective optimization model to optimize the allocation of water resources among stakeholders. The results showed that the serious water resources conflict can be prevented by changing the provincial-based operation mode and changing the existing agricultural and industrial water resource allocation. Xu and Lei [14] used the Gini coefficient and health resource density index to analyze the fairness of health human resources and took Hubei Province of China as an example for empirical analysis. The results showed that the equity of health human resources by population distribution was good, but the equity by geographical distribution was poor. Therefore, the government should take the geographical area as the factor of human resource allocation. Chen et al. [15] proposed an active resource allocation method based on cloud computing, which is conducive to improving the accuracy of resource prediction. Then, a multiobjective resource allocation optimization model was established, and the traditional algorithm was improved to further shorten the resource allocation time. In addition, Zhao et al. [16] also studied the fair allocation of resources using cloud computing. They proposed a new dominant resource allocation mechanism with bottleneck fairness. The experiments showed that the proposed resource allocation method is more efficient than the traditional method in terms of high resource utilization. Elloumi et al. [17] proposed a decision tree-based business process resource allocation problem minimization method. Zhao et al. [18] proposed a resource allocation method based on improved hybrid particle swarm optimization algorithm, which made the resource allocation optimization problem more reasonable. Li et al. [19] studied the allocation of financial resources and focused on the effectiveness of financial resource allocation. After defining and analyzing the effectiveness of fiscal resource allocation, they also discussed the relationship between the effectiveness of fiscal resource allocation and economic development. Tao et al. [20] used data envelopment analysis to study resource allocation. The network structure was introduced when studying the resource allocation problem, and the cost was considered in the network flow, and then the optimal resource allocation scheme was found.

\section{Model Description}

3.1. Selection and Description of Prediction Model. Grey system theory is the result of the interaction of many factors. These factors are unknown in the relationship, which is also the characteristic of the theory. The 
unknownness and uncertainty of these factors become the grey characteristics of the system. Grey prediction models usually use cumulative generation and cumulative reduction generation methods to transform the original data into a generation sequence with strong regularity and then construct differential equations based on the generation sequence for modeling prediction [21]. Since the generated sequence has a stronger regularity than the previous sequence, the data increase exponentially. By finding out the law of its change, the purpose of prediction can be achieved. The grey prediction method has obvious advantages, that is, only a small amount of data is needed to predict the corresponding short-term data and the effect is good. The disadvantage is that the prediction accuracy will deteriorate when the original data are more discrete.

One of the common methods of curve fitting is the least squares method. This method is a mathematical optimization method that minimizes the sum of squares of errors to find the best function match for a set of data [22]. The least squares curve fitting method is a fitting method that can achieve the global optimum of the error in order to find the functional relationship between the independent variable and the dependent variable. It can better express the characteristics of the data and does not require the curve to accurately pass through all points. The curve fitting method has the advantages of simple principle and easy operation, and can reduce the error caused by scattered points and improve the calculation accuracy of the model. so as to improve the accuracy of model operation. The disadvantage is that the method is linear estimation, which has been defaulted to be linear, so it is subjective.

Therefore, this paper uses the above two methods to predict the market share of labor resources, the industrial growth rate, the employment contribution rate, and the GDP in 2021 and selects more accurate prediction results by comparing and analyzing the prediction results.

3.1.1. Grey Prediction Model. At present, the most widely used grey prediction model is the GM $(1,1)$ model of a variable and first-order differential about the prediction of sequence. GM $(1,1)$ model is one of the most commonly used grey models. Its grey equation is a first-order differential equation containing only a single variable [23].

(1) Grey Prediction Model Construction. First, let $X^{(0)}=\left(X^{(0)}(1), X^{(0)}(2), \ldots, X^{(0)}(n)\right)$ be the original sequence, and then generate a cumulative sequence.

$$
X^{(1)}=\left(X^{(1)}(1), X^{(1)}(2), \ldots, X^{(1)}(n)\right)=\left(X^{(1)}(1),\left(X^{(1)}(1)+X^{(0)}(2), \ldots, X^{(1)}(n-1)+\cdots X^{(0)}(n)\right)\right)
$$

Second, the grey derivative is defined as

$$
d(k)=X^{(0)}(k)=X^{(1)}(k)-X^{(1)}(k-1) .
$$

Third, let $Z^{(1)}$ be the mean sequence of the sequence $X^{(1)}$, and the calculation formula is as follows:

$$
\begin{aligned}
Z^{(1)}(k) & =0.5 X^{(1)}(k)+0.5 X^{(1)}(k-1) \\
& =\left(Z^{(1)}(2), Z^{(1)}(3), \ldots, Z^{(1)}(n)\right) \quad(k=2,3, \ldots, n) .
\end{aligned}
$$

Fourth, the grey differential equation and whitening differential equation of GM $(1,1)$ are established. In the formula, $X^{(0)}(k)$ is called grey derivative, $a$ is called development coefficient, $Z^{(1)}(k)$ is called whitening background value, and $b$ is called the grey action.

$$
\begin{gathered}
X^{(0)}(k)+a Z^{(1)}(k)=b \quad(k=2,3, \ldots, n), \\
\frac{\mathrm{d} X^{(1)}}{\mathrm{dt}}+a X^{(1)}(t)=b .
\end{gathered}
$$

Finally, the least squares method is used to estimate the parameters and solve the equation.

$$
\left\{\begin{array}{l}
X^{(0)}(2)+a Z^{(1)}(2)=b \\
X^{(0)}(3)+a Z^{(1)}(3)=b \\
\vdots \vdots \\
X^{(0)}(n)+a Z^{(1)}(n)=b .
\end{array}\right.
$$

Note $\quad Y_{N}=\left(X^{(0)}(2), X^{(0)}(3), \ldots, X^{(0)}(n)\right)^{T}, u=$ $(a, b)^{T}, B=\left[\begin{array}{cc}-Z^{(1)}(2) & 1 \\ -Z^{(1)}(3) & 1 \\ \vdots & \vdots \\ -Z^{(1)}(n) & 1\end{array}\right]$; then, GM (1, 1$)$ can be expressed as a matrix equation.

The parameter vector is determined by formula (6). In the formula, $u$ is called the parameter vector.

$$
u=(a, \hat{b})^{T}=\left(B^{T} B\right)^{-1} B^{T} Y_{N}
$$

So, we can get the solution equation and then calculate the predicted value.

$$
X^{(1)}(k+1)=\left(X^{(0)}(1)-\frac{b}{a}\right) e^{-\mathrm{ak}}+\frac{b}{a},(\mathrm{k}=1,2, \ldots, n-1) .
$$


However, there may be many research problems that are not suitable for GM $(1,1)$ prediction model, so it is necessary to carry out residual test and posterior difference test.

(2) Grey Prediction Model Test. First, calculate the average value of the original sequence:

$$
\bar{X}^{(0)}=\frac{1}{n} \sum_{i=1}^{n} X^{(0)}(i) .
$$

Second, calculate the mean square error of the original sequence:

$$
S_{1}=\left\{\frac{\sum_{i=1}^{n}\left[X^{(0)}(i)-\bar{X}^{(0)}\right]^{2}}{n-1}\right\}^{1 / 2}
$$

Third, calculate the average value of residual:

$$
\bar{\Delta}^{(0)}=\frac{1}{n} \sum_{i=1}^{n} \bar{\Delta}^{(0)}(i) .
$$

Fourth, calculate the mean square error of residuals:

$$
S_{1}=\left\{\frac{\sum_{i=1}^{n}\left[\Delta^{(0)}(i)-\bar{\Delta}^{(0)}\right]^{2}}{n-1}\right\}^{1 / 2} .
$$

Finally, calculate the mean square error ratio and small residual probability. In the formula, $C$ is the mean square error ratio and $P$ is the small residual probability.

$$
\begin{aligned}
& C=\frac{S_{2}}{S_{1}} \\
& P=p\left\{\left|\Delta^{(0)}(i)-\bar{\Delta}^{(0)}\right|<0.6745 S_{1}\right\}, \\
& S_{0}=0.6745 S_{1}, \\
& \lambda=\left|\Delta^{(0)}(i)-\bar{\Delta}^{(0)}\right|, \\
& P=p\left\{\lambda<S_{0}\right\} .
\end{aligned}
$$

For a given $C_{0}>0$, when $C<C_{0}$, the model is called mean square error ratio qualified model; for a given $P_{0}>0$, when $P>P_{0}$, the model is called small residual probability qualified model.

3.1.2. Curve Fitting Model. The curve fitting problem is to find a simple function so that the curve does not have to go through all data points, but as close as possible to each data point. This simple function is called fitting function [24]. First, we select the basis function and then solve the linear function $p(t)=a+b t$, where $a$ and $b$ are the parameters to be determined. In order to make the graph of $p(t)$ as close as possible to each data point, we minimize
$P=\sum_{i=0}^{n}\left(p\left(t_{i}\right)-c\left(t_{i}\right)\right)^{2}$, that is, find $a$ and $b$ to minimize the function in the following formula:

$$
I(a, b)=\sum_{i=0}^{n}\left(a+b t_{i}-c\left(t_{i}\right)\right)^{2} .
$$

Then, we get the necessary conditions for extreme value by the following formula:

$$
\begin{aligned}
& \left\{\begin{array}{l}
\frac{\partial I}{\partial a}=\sum_{i=0}^{n} 2\left(a+b t_{i}-c\left(t_{i}\right)\right)=0 \\
\frac{\partial I}{\partial b}=\sum_{i=0}^{n} 2\left(a+b t_{i}-c\left(t_{i}\right)\right) t_{i}=0
\end{array}\right. \\
& \left\{\begin{array}{l}
a \sum_{i=0}^{n} 1+b \sum_{i=0}^{n} t_{i}=\sum_{i=0}^{n} c\left(t_{i}\right) \\
a \sum_{i=0}^{n} t_{i}+b \sum_{i=0}^{n} t_{i}^{2}=\sum_{i=0}^{n} c\left(t_{i}\right) t_{i} .
\end{array}\right.
\end{aligned}
$$

Finally, the data are substituted into the formula to solve $a$ and $b$, and the fitting results are obtained.

In summary, the flowchart of the labor market resource prediction model of the three major industries is shown in Figure 1.

3.2. Principal Component Analysis. Principal component analysis is an index dimension reduction method, which integrates many related indexes in the research sample into a few indexes. This can not only reduce the difficulty of the analysis problem but also minimize the loss of many kinds of valuable information in the index, so as to ensure the accuracy of the analysis results. Among them, each comprehensive indicator is called the principal component, and each principal component is no longer related to each other. The first principal component is the comprehensive indicator with the largest corresponding variance, and the second principal component is the comprehensive indicator with the second largest variance $[25,26]$. The function of principal component analysis is to reduce the workload of index selection and determine whether the weight is objective and reasonable. The disadvantage is that to ensure that the cumulative contribution rate of the first several principal components extracted reaches a high level, the amount of information after variable dimension reduction needs to be maintained at a high level.

3.2.1. Standardization of Raw Data. Assuming that there are $m$ evaluation objects and $n$ evaluation criteria, the $j$ th index of the $i$ th evaluation object is denoted as $x_{i j}$, and each index $x_{i j}$ is converted into $\overline{x_{i j}}$. In the formula, $\overline{x_{j}}$ and $S_{j}$ are the sample mean and standard deviation of the $j$ th index, and the standardized index variables are 




FIGURE 1: Flowchart of labor market resource prediction model of three major industries.

$$
\begin{aligned}
& \overline{x_{j}}=\frac{1}{m} \sum_{i=1}^{m} x_{i j}, \\
& S_{j}=\sqrt{\frac{1}{m-1} \sum_{i=1}^{m}\left(x_{i j}-\overline{x_{j}}\right)^{2},} \\
& \overline{x_{i j}}=\frac{x_{i j}-\overline{x_{j}}}{S_{j}} .
\end{aligned}
$$

3.2.2. Calculating Correlation Coefficient Matrix. The correlation coefficient matrix is calculated according to formulas (16) and (17), and $r_{i i}=1, r_{i j}=r_{j i} . r_{i j}$ in the formula refers to the correlation coefficients of the $i$ th index and the $j$ th index.

$$
\begin{aligned}
R & =\left(r_{i j}\right)_{p * p}, \\
r_{i j} & =\frac{\sum_{k=1}^{n}\left(x_{k i}-\overline{x_{i}}\right)\left(x_{i j}-\overline{x_{j}}\right)}{\sqrt{\sum_{k=1}^{n}\left(x_{k i}-\overline{x_{i}}\right)^{2} \sum_{k=1}^{n}\left(x_{i j}-\overline{x_{j}}\right)^{2}}} .
\end{aligned}
$$

3.2.3. Computing Eigenvalues and Eigenvectors. The eigenvalue $\lambda_{1} \geq \lambda_{2} \geq \cdots \geq \lambda_{m} \geq 0$ of the correlation coefficient matrix $R$ and the corresponding eigenvector $u 1$, $u 2, \ldots, u m$ are calculated, where $m$ new indicator variables are composed of the eigenvector. In the formula, $y_{1}$ is the first principal component, $y_{2}$ is the second principal component, ..., and $y_{m}$ is the $m$ th principal component.

$$
\left\{\begin{array}{l}
y_{1}=u_{11} \tilde{x}_{1}+u_{21} \tilde{x}_{2}+\ldots+u_{m 1} \tilde{x}_{m} \\
y_{2}=u_{12} \tilde{x}_{1}+u_{22} \tilde{x}_{2}+\cdots+u_{m 2} \tilde{x}_{m} \\
\ldots \ldots \ldots \ldots+\ldots \\
y_{m}=u_{1 m} \tilde{x}_{1}+u_{2 m} \tilde{x}_{2}+\cdots+u_{m m} \tilde{x}_{m}
\end{array}\right.
$$

\subsubsection{Extracting Principal Component Factors}

(1) Calculate the information contribution rate of eigenvalues $\lambda_{j}(j=1,2, \ldots, m)$.

$$
b_{j}=\frac{\lambda_{j}}{\sum_{k=1}^{m} \lambda_{k}} \quad(j=1,2, \ldots, m) .
$$


(2) If the variance contribution rate of the first principal component is greater than $85 \%$, the first principal component is selected directly. If the variance contribution rate of the first principal component is less than $85 \%$, the cumulative contribution rate of the eigenvalues is calculated using the following equation:

$$
\alpha_{p}=\frac{\sum_{k=1}^{p} \lambda_{k}}{\sum_{k=1}^{m} \lambda_{k}}
$$

(3) Calculate the composite score. Among them, $b_{j}$ is the information contribution rate of the $j$ th principal component, which can be evaluated according to the comprehensive score.

$$
Z=\sum_{j=1}^{p} b_{j} y_{j}
$$

In summary, the structural flowchart of principal component analysis is shown in Figure 2.

\section{Example Analysis}

4.1. Data Preprocessing. By collecting the data, we obtain the data of the market share, industrial growth rate, employment contribution rate, and the pulling ability of the three industries to GDP. The summary results are shown in Tables 1-5. Among them, the data in Tables 1 and 5 are from the Business Society, the data in Table 2 are from the China Economic Information Network, and the data in Table 4 are from the Prospective Industry Research Institute of the Ministry of Human Resources and Social Affairs.

According to the above industrial amount, the growth rates of the three industries over the years are shown in Table 2.

4.2. Grey GM $(1,1)$ Prediction. Based on the data of market share, industrial growth rate, and employment contribution rate of China's three major industries from 2011 to 2020 and the principle of grey prediction model, this paper forecasts China's three major industries in 2021 to test the accuracy of the model and make the prediction more convincing. Among them, the grey prediction model results of China's primary industry market share are

$X^{(1)}(k+1)=54.2745 e^{0.066 k}-50.1945(\mathrm{k}=0,1,2, \ldots, 20)$.

Substituting the data of each year into the above equation, the calculation results are accumulated and reduced to obtain the simulation value, residual variation, and relative variation of the original sample, as shown in Table 6.

It can be seen from the above that the residuals are not too large and are within an acceptable range, so this model can be used for prediction. In order to improve reliability, the following posterior difference test is performed.

Calculate the average value of the original sequence:

$$
\bar{X}^{(0)}=\frac{1}{10} \sum_{i=1}^{10} X^{(0)}(i)=4.84 .
$$

Calculate the mean square error of the original sequence:

$$
S_{1}=\left\{\frac{\sum_{i=1}^{10}\left[X^{(0)}(i)-\bar{X}^{(0)}\right]^{2}}{9}\right\}^{1 / 2}=1.66 .
$$

Calculate the average value of residual:

$$
\bar{\Delta}^{(0)}=\frac{1}{10} \sum_{i=1}^{10} \bar{\Delta}^{(0)}(i)=0.03 .
$$

Calculate the mean square error of residuals:

$$
S_{2}=\left\{\frac{\sum_{i=1}^{10}\left[\Delta^{(0)}(i)-\bar{\Delta}^{(0)}\right]^{2}}{9}\right\}^{1 / 2}=1.44 .
$$

Calculate mean variance ratio $C$ :

$$
C=\frac{S_{2}}{S_{1}}=0.871 .
$$

Calculate small residual probability:

$$
\begin{aligned}
S_{0} & =0.6745 S_{1}=1.12, \\
\lambda & =\left|\Delta^{(0)}(i)-\bar{\Delta}^{(0)}\right| \\
& =(0.03,1.31,0.23,0.26,0.10,0.84,0.56,1.46,1.95,3.14) .
\end{aligned}
$$

From the above data, $P=p\left\{\lambda<S_{0}\right\}=0.6$. As can be seen from Table 7, $P_{0}=0.7, C_{0}=0.65, P<P_{0}$, and $C>C_{0}$, so the grey prediction model is not qualified. Therefore, this model cannot be used to predict the data of three major industries in 2021.

4.3. Curve Fitting Prediction. In this paper, we uses polynomial fitting method to predict the three major industry market share, industrial growth rate, employment contribution rate, and the ability to drive GDP in 2021 according to China's three major industry data from 2011 to 2020. The three major industry trends of market share are shown in Figure 3.

Through the above fitting of previous data, it can be seen that the market share of the primary industry approached $4.19 \%$, that of the secondary industry approached $32.31 \%$, and that of the tertiary industry approached $62.4855 \%$ in 2021. After normalizing the data, the market share of the primary industry is close to $4.2 \%$, the market share of the secondary industry is close to $32.6 \%$, and the market share of the tertiary industry is close to $63.1 \%$ in 2021 .

Similarly, following the above prediction method and using the fitting curve in Excel software, the growth rate, 


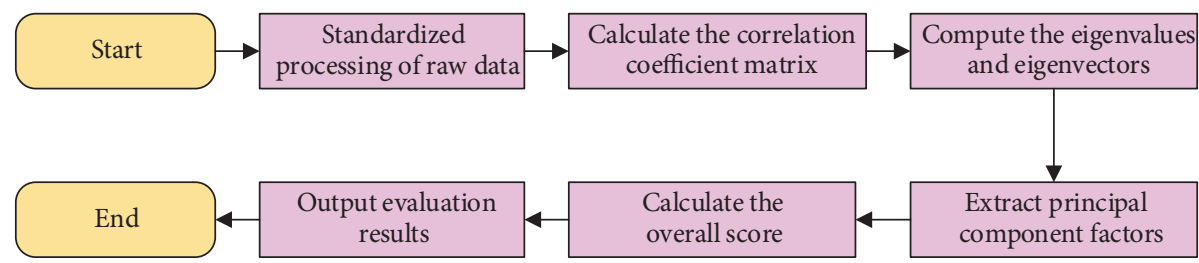

FIGURE 2: Structural flowchart of principal component analysis.

TABLE 1: Summary of market share data of three major industries over the years (unit: \%).

\begin{tabular}{lcccccccccc}
\hline Industry & 2011 & 2012 & 2013 & 2014 & 2015 & 2016 & 2017 & 2018 & 2019 & 2020 \\
\hline Primary industry & 4.08 & 5.04 & 4.21 & 4.51 & 4.44 & 4.01 & 4.62 & 4.07 & 3.95 & 9.45 \\
Secondary industry & 52.04 & 49.97 & 48.54 & 45.57 & 39.71 & 35.97 & 34.23 & 34.43 & 32.57 & 43.29 \\
Tertiary industry & 43.89 & 45.00 & 47.25 & 49.91 & 55.85 & 60.02 & 61.14 & 61.50 & 63.48 & 47.25 \\
\hline
\end{tabular}

TABLE 2: Summary of calendar year data of the three major industries (unit: 100 billion yuan)

\begin{tabular}{lrrrrrr}
\hline Industry & 2015 & 2016 & 2017 & 2018 & 2019 & 2020 \\
\hline $\begin{array}{l}\text { Primary } \\
\text { industry }\end{array}$ & 60862 & 63673 & 65463 & 64745 & 70474 & 77754 \\
$\begin{array}{l}\text { Secondary } \\
\text { industry }\end{array}$ & 282040 & 296548 & 334623 & 364835 & 380671 & 384255 \\
$\begin{array}{l}\text { Tertiary } \\
\text { industry }\end{array}$ & 346150 & 383365 & 427032 & 489701 & 535371 & 553977 \\
\hline
\end{tabular}

TABle 3: Summary of annual growth rate data of three major industries (unit: \%).

\begin{tabular}{lccccc}
\hline Industry & 2016 & 2017 & 2018 & 2019 & 2020 \\
\hline Primary industry & 4.6 & 2.8 & -1.1 & 8.8 & 10.3 \\
Secondary industry & 5.1 & 12.8 & 9 & 4.3 & 0.9 \\
Tertiary industry & 10.8 & 11.4 & 14.7 & 9.3 & 3.5 \\
\hline
\end{tabular}

TABLE 4: Summary of employment contribution rate of three major industries.

\begin{tabular}{lcccccc}
\hline Industry & 2015 & 2016 & 2017 & 2018 & 2019 & 2020 \\
\hline $\begin{array}{l}\text { Primary } \\
\text { industry }\end{array}$ & 60862 & 63673 & 65463 & 64745 & 70474 & 77754 \\
$\begin{array}{l}\text { Secondary } \\
\text { industry }\end{array}$ & 282040 & 296548 & 334623 & 364835 & 380671 & 384255 \\
$\begin{array}{l}\text { Tertiary } \\
\text { industry }\end{array}$ & 346150 & 383365 & 427032 & 489701 & 535371 & 553977 \\
\hline
\end{tabular}

employment contribution rate, and pulling ability of the three major industries to GDP are obtained as follows: the growth rate of the primary industry is close to $10.3 \%$, the growth rate of the secondary industry is close to $4.0565 \%$, and the growth rate of the tertiary industry is close to $7.352 \%$. The employment contribution rate of the primary industry is close to $24.3533 \%$, the employment contribution rate of the second industry is close to $27.1607 \%$, and the employment contribution rate of the tertiary industry is close to $48.8929 \%$. The pulling ability of the primary industry to GDP is close to 0.1933 , that of the second industry to GDP is close to 1.117 , and that of the tertiary industry to GDP is close to 1.5469 .
4.4. Principal Component Analysis. First of all, by using the grey prediction method and the curve fitting method to predict the four indicators of market share, industrial growth rate, employment contribution rate, and the pulling ability to GDP, it is found that the results obtained by the curve fitting method are more accurate. Therefore, this paper uses the data predicted by the curve fitting method to carry out the principal component analysis. The summary results of the indicators of the three major industries are shown in Table 8.

Second, the original data are standardized by using SPSS software, and the standardized data of each index of the three major industries are shown in Table 9.

Third, the correlation coefficient matrix of variables are calculated by using SPSS software, and the results are shown in Table 10.

Fourth, we use SPSS software to extract the principal component factors, and the specific process is shown in Table 11 and Figure 4.

Table 11 shows the variance interpretation table of factor analysis, which is the calculation result of correlation coefficient matrix eigenvalue, variance contribution rate, and cumulative variance contribution rate.

Figure 4 shows a factor gravel graph, where the abscissa is the number of factors and the ordinate is the eigenvalue. It can be seen from the figure that the higher the eigenvalue of the factor is, the greater the contribution to explaining the original variable is. In addition, we can see that the principal component is the first, accounting for $75.992 \%$. Since the index has exceeded $65 \%$, it can be used to approximately replace other indicators to characterize the strength.

In addition, the component score coefficient matrix can be obtained, as shown in Table 12 .

Finally, we use formula (21) to calculate the comprehensive score and the calculation process, and the results are as follows. It can be seen from the calculation results that the comprehensive score of the tertiary industry is the highest, followed by the secondary industry, and the comprehensive score of the primary industry is the lowest. It shows that the tertiary industry is a strong industry. The flow direction of labor resources will change from the primary and secondary industries to the tertiary industry. 
TABLE 5: Summary of GDP pulling ability of three major industries over the years.

\begin{tabular}{lcccccccccc}
\hline Industry & 2011 & 2012 & 2013 & 2014 & 2015 & 2016 & 2017 & 2018 & 2019 & 2020 \\
\hline Primary industry & 0.4 & 0.4 & 0.3 & 0.3 & 0.3 & 0.3 & 0.3 & 0.3 & 0.2 & 0.2 \\
Secondary industry & 5 & 3.9 & 3.8 & 3.4 & 2.8 & 2.5 & 2.4 & 2.3 & 1.9 & 1 \\
Tertiary industry & 4.4 & 3.5 & 3.7 & 3.7 & 3.9 & 4.1 & 4.2 & 4.2 & 3.8 & 1.1 \\
\hline
\end{tabular}

TABLE 6: Grey system prediction and verification of primary industry market share in China from 2011 to 2020.

\begin{tabular}{lcccc}
\hline Year & Original value & Predictive value & Residual & Relative variation (\%) \\
\hline 2011 & 4.08 & 4.08 & 0.000 & 0.00 \\
2012 & 5.04 & 3.70 & 1.337 & 26.53 \\
2013 & 4.21 & 3.96 & 0.254 & 6.04 \\
2014 & 4.51 & 4.23 & 0.285 & 6.31 \\
2015 & 4.44 & 4.51 & -0.074 & -1.66 \\
2016 & 4.01 & 4.82 & -0.812 & -20.24 \\
2017 & 4.62 & 5.15 & -0.531 & -11.49 \\
2018 & 4.07 & 5.50 & -1.432 & -35.19 \\
2019 & 3.95 & 5.88 & -1.928 & -48.80 \\
2020 & 9.45 & 6.28 & 3.171 & 33.56 \\
\hline
\end{tabular}

TABle 7: Posterior difference test.

\begin{tabular}{lcccc}
\hline Accuracy grade & I & II & III & \\
\hline$P$ & $>0.95$ & $>0.8$ & $>0.7$ & $\leq 0.7$ \\
$C$ & $<0.35$ & $<0.5$ & $<0.65$ & $\geq 0.65$ \\
\hline
\end{tabular}


Figure 3: Trend lines of market share in three major industries. 
TABLE 8: Summary of indicators of three major industries.

\begin{tabular}{lccc}
\hline Indicators & Primary industry & Secondary industry & Tertiary industry \\
\hline Market share (\%) & 4.2 & 32.6 & 63.1 \\
Industrial growth rate (\%) & 10.3 & 4.0565 & 7.352 \\
Employment contribution rate (\%) & 24.3533 & 27.1607 & 48.8929 \\
The pulling ability to GDP & 0.1933 & 1.117 & 1.5496 \\
\hline
\end{tabular}

TABLE 9: Summary of standardized data on indicators of three major industries.

\begin{tabular}{lccc}
\hline Indicators & Primary industry & Secondary industry & Tertiary industry \\
\hline Market share & 0.98135 & 0.02376 & 1.01167 \\
Industrial growth rate & 0.98135 & 1.01766 & 0.03631 \\
Employment contribution rate & 0.67879 & 0.46957 & 1.14836 \\
The pulling ability to GDP & 1.09783 & 0.23895 & 0.85888 \\
\hline
\end{tabular}

TABLE 10: Correlation matrix for indicators.

\begin{tabular}{lcccc}
\hline Indicators & Market share & Industrial growth rate & Employment & The pulling ability to GDP \\
\hline Market share & 1 & 0.454 & 0.922 & 0.974 \\
Industrial growth rate & 0.454 & 1 & 0.073 & 0.645 \\
Employment contribution rate & 0.922 & 0.073 & 1 & 0.810 \\
The pulling ability to GDP & 0.974 & 0.645 & 0.810 & 1 \\
\hline
\end{tabular}

TABle 11: Total variance explanation.

\begin{tabular}{|c|c|c|c|c|c|c|}
\hline \multirow{2}{*}{ Element } & \multicolumn{3}{|c|}{ Initial eigenvalue } & \multicolumn{3}{|c|}{ The sum of squares of load extracted } \\
\hline & Grand total & Variance proportion & Accumulation & Grand total & Variance proportion & Accumulation \\
\hline Market share & 3.040 & 75.992 & 75.992 & 3.040 & 75.992 & 75.992 \\
\hline Industrial growth rate & 0.960 & 24.008 & 100 & & & \\
\hline Employment contribution rate & $5.441 E-16$ & $1.360 E-14$ & 100 & & & \\
\hline The pulling ability to GDP & $-1.781 E-16$ & $-4.451 E-15$ & 100 & & & \\
\hline
\end{tabular}

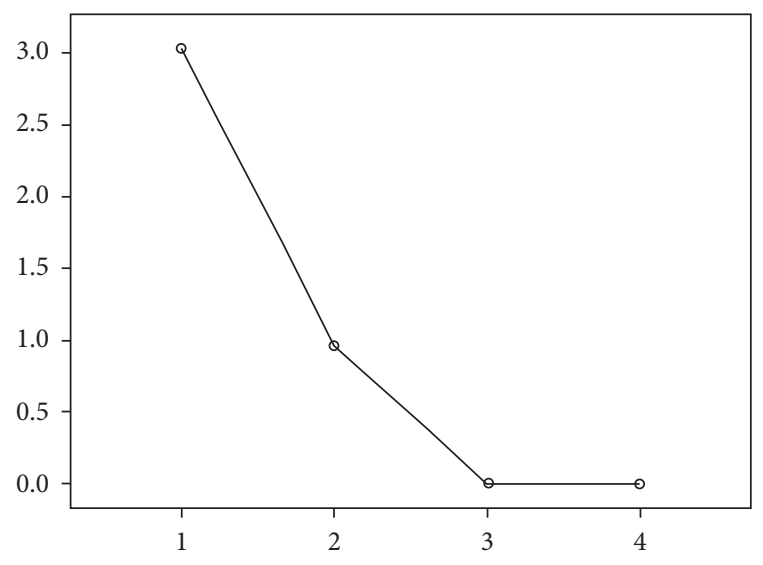

FIGURE 4: Factor gravel map.

In recent years, the labor resources of the primary industry have been in a state of outflow. With the continuous upgrading of the industrial structure, the number of employees in the manufacturing industry will continue to decrease. The low-tech and simple manual workers will outflow from the manufacturing industry, and the labor that can adapt to the transformation needs will flow to high-end manufacturing, modern science and technology industries, and service industries. In addition, with government regulation of the real estate market and the
TABLE 12: Component score coefficient matrix.

\begin{tabular}{lc}
\hline Indicators & Element 1 \\
\hline Market share & 0.326 \\
Industrial growth rate & 0.186 \\
Employment contribution rate & 0.284 \\
The pulling ability to GDP & 0.327 \\
\hline
\end{tabular}

restructuring of the construction industry, labor will flow slowly from the construction industry as a secondary industry to other industries. The tertiary industry is the focus of labor transfer. When labor flows into the traditional service industry, the demand for labor in highend services such as the financial industry, software industry, and technical service industry will be greater in the future, and new labor industry agglomeration will be formed.

$$
\begin{aligned}
F_{1} & =0.326 \times(-0.98791)+(-0.186) \times 0.98135+ \\
0.284 & \times(-0.67879)+0.327 \times(-1.09783)=-1.0563, \\
F_{2} & =0.326 \times(-0.02376)+(-0.186) \times(-1.01766)+ \\
0.284 & \times(-0.46957)+0.327 \times 0.23895=0.1263, \\
F_{3} & =0.326 \times 1.01167+(-0.186) \times 0.03631+ \\
0.284 & \times 1.14836+0.327 \times 0.85888=0.9300 .
\end{aligned}
$$




\section{Conclusions and Suggestions}

5.1. Conclusions. The labor force is the most critical factor in the three industries, and its composition and allocation efficiency determines the development speed and output value of the three industries. Therefore, this paper first uses the grey prediction method and curve fitting method to predict the market share, industrial growth rate, employment contribution rate, and GDP pulling capacity of China's three major industries in 2021 and then uses the principal component analysis method to obtain these weights and calculate the strength of each industry. Through the strong degree, we can determine the strong industry in the three major industries, so as to realize the optimization of labor market resource allocation. The results of empirical analysis show that the tertiary industry is a strong industry in the three major industries. Therefore, based on the current labor structure and empirical results, we propose to optimize the efficiency of resource allocation in China's labor market.

5.2. Suggestions. Through the prediction and analysis of the three major industries, we put forward the following suggestions for the optimal allocation of labor market resources combined with the new requirements of the allocation of labor resources.

(1) Establish labor market price system: the government should compare the supply and demand of talents at different levels through macrocontrol means and formulate the index system of labor price at different levels as soon as possible so that both sides of labor supply and demand can achieve the optimal allocation of labor resources based on market prices through supply and demand relations and competition mechanisms.

(2) Establish a unified urban and rural labor market system to achieve free flow of labor: this can not only promote the optimal allocation of labor resources but also effectively promote fair employment. The free flow of labor resources can break the discriminatory, protective, and blockaded barriers. Under the influence of market signals, the free movement and allocation of labor across regions are realized.

(3) Establish a fully competitive market: the marketoriented labor optimization requires that the market must be a fully competitive market. An effective labor market must be an open, fair, and just competition market without discrimination and privilege. In addition, the government should improve the market mechanism and regulate market behavior. Only in this way can we achieve the optimal allocation of labor resources and ensure the fairness of the employment process and eliminate employment discrimination.

\section{Data Availability}

The data used to support the findings of this study are available from the corresponding author upon request.

\section{Conflicts of Interest}

The author declares that there are no conflicts of interest.

\section{References}

[1] G. Yu and Z. Lu, "Rural credit input, labor transfer and urbanrural income gap: evidence from China," China Agricultural Economic Review, vol. 13, no. 4, pp. 872-893, 2021.

[2] S. X. Wang and F. Yu Benjamin, "Labor mobility barriers and rural-urban migration in transitional China," China Economic Review, vol. 53, pp. 211-224, 2019.

[3] F. W. Chen, Y. Tan, F. Chen, and Y. Q. Wu, "Enhancing or suppressing: the effect of labor costs on energy intensity in emerging economies," Energy, vol. 214, Article ID 118964, 2020.

[4] L. Zhang, L. Chen, W. Yu, and J. Lu, "Chinese labor-intensive industries under trade protectionism-characteristics, comprehensive strategies and educational revelations based on economic comparative advantage," International Journal of Electrical Engineering Education, Article ID $002072092199823,2021$.

[5] J. Wang, Y. Hu, and Z. Zhang, "Skill-biased technological change and labor market polarization in China," Economic Modelling, vol. 100, no. 4, Article ID 105507, 2021.

[6] I. Zaitseva, O. Malafeyev, O. Pankratova, L. Novozhilova, and V. Smelik, "Software implementation of game -theoretic models accompanying labor resource allocation processes," in Proceedings of the International Conference on Numerical Analysis and Applied Mathematics (ICNAAM), vol. 2293, Article ID 420021, Rhodes, Greece, September 2020.

[7] I. V. Zaitseva, D. V. Shlaev, N. V. Poddubnaya, G. I. Linets, T. V. Minkina, and V. I. Petrenko, "Research of the labor resource redeployment by mathematical methods of optimal management," IOP Conference Series: Earth and Environmental Science, vol. 421, no. 3, p. 7, Article ID 032025, 2020.

[8] I. V. Zaitseva, O. A. Malafeyev, K. I. Kostyukov et al., "Dynamic programming method in the tasks of optimal labor capital distribution programs," in Proceedings of the 2nd International Scientific Conference on Agribusiness, Environmental Engineering and Biotechnologies (AGRITECH), vol. 421, Article ID 032024, Amsterdam, Netherlands, March 2020.

[9] I. V. Zaitseva, A. N. Ermakova, and S. I. Lugovskoy, "Workforce planning distribution of the region's results," Research Journal of Pharmaceutical, Biological and Chemical Sciences, vol. 8, no. 1, pp. 1862-1866, 2021.

[10] L. Y. Shi, "Labor industry allocation, industrial structure optimization, and economic growth," Discrete Dynamics in Nature and Society, vol. 2021, Article ID 5167422, 2021.

[11] J. Zhou, P. Wang, and L. Xie, "Research on resource allocation optimization of smart city based on big data," IEEE Access, vol. 8, no. 99, 158861 pages, Article ID 158852, 2020.

[12] Q. Wen, L. Zhang, X. Fei, and J. Li, "Discussions about water resources allocation," IOP Conference Series: Earth and Environmental Science, vol. 267, no. 2, Article ID 022030, 2019.

[13] M. Kazemi, O. Bozorg-Haddad, E. Fallah-Mehdipour, and $\mathrm{X}$. Chu, "Optimal water resources allocation in transboundary river basins according to hydropolitical consideration," Environment, Development and Sustainability, pp. 1-19, 2021.

[14] Z. Xu and X. Lei, "Analysis on equity of health human resource allocation in Hubei Province based on the Gini coefficient and a HRDI model," Journal of Physics: Conference Series, vol. 1941, no. 1, p. 8, Article ID 012063, 2021. 
[15] J. Chen, Y. L. Wang, and T. Liu, "A proactive resource allocation method based on adaptive prediction of resource requests in cloud computing," EURASIP Journal on Wireless Communications and Networking, vol. 2021, no. 1, pp. 1-20, 2021.

[16] L. Zhao, M. Du, and L. Chen, "A new multi-resource allocation mechanism: a tradeoff between fairness and efficiency in cloud computing," China Communications, vol. 15, no. 3, pp. 57-77, 2018.

[17] F. B. Elloumi, Sellami, S. Bhiri, and Z. Maamar, "Avoiding resource misallocations in business processes," in Proceedings of the 16th International Workshop on Algorithms, Models and Tools for Parallel Computing on Heterogeneous Platforms (HeteroPar), vol. 32, no. 15, Article ID e4888, Ischia, Italy, May 2020.

[18] W. Zhao, Q. Zeng, G. Zheng, and L. Yang, "The resource allocation model for multi-process instances based on particle swarm optimization," Information Systems Frontiers, vol. 19, no. 5, pp. 1057-1066, 2017.

[19] Z. Li, S. Chen, and S. Chen, "Statistical measure of validity of financial resources allocation," Eurasia Journal of Mathematics, Science and Technology Education, vol. 13, no. 12, pp. 1-11, 2017.

[20] X. Tao, B. Xiong, and Q. An, "DEA-based centralized resource allocation with network flows," International Transactions in Operational Research, vol. 28, no. 2, pp. 926-958, 2021.

[21] Y.-C. Hu, "Constructing grey prediction models using grey relational analysis and neural networks for magnesium material demand forecasting," Applied Soft Computing, vol. 93, Article ID 106398, 2020.

[22] Z. Zafar and M. Aslam, "An adaptive weighted least squares ratio approach for estimation of heteroscedastic linear regression model in the presence of outliers," Communications in Statistics-Simulation and Computation, no. 1, pp. 1-11, 2021.

[23] Y. C. Hu, "Energy demand forecasting using a novel remnant GM(1, 1) model," Soft Computing, vol. 24, no. 18, 2020.

[24] S. Wang, Y. Ning, H. Shi, and X. Chen, "A new uncertain linear regression model based on slope mean," Journal of Intelligent and Fuzzy Systems, vol. 25, no. 20, pp. 1-10, 2021.

[25] Z. Liu, Z. Jiang, C. Xu, G. Cai, and J. Zhan, "Assessment of provincial waterlogging risk based on entropy weight TOPSIS-PCA method," Natural Hazards, vol. 108, no. 2, pp. 1-23, 2021.

[26] S. Xu, Y. Cui, C. Yang et al., "The fuzzy comprehensive evaluation (FCE) and the principal component analysis (PCA) model simulation and its applications in water quality assessment of Nansi Lake Basin, China," Environmental Engineering Research, vol. 26, no. 2, Article ID 200022, 2020. 